\title{
Correlation of plasma vitamin D levels with coronary collateral circulation
}

\section{Fardin Mirbolouk, Arsalan Salari, Asieh Ashouri, Nazila Ghoreishi, Amin Karimi, Mani Moayerifar, Zahra Ahmadnia, Mahboobeh Gholipour*, Alimohammad Sadeghi Meibodi*}

Cardiovascular Diseases Research Center, Department of Cardiology, Heshmat Hospital, School of Medicine, Guilan University of Medical Sciences, Rasht, Iran

\section{*Correspondence to Mahboobeh Gholipour, Email: \\ drmgholipur@gmail.com and Alimohammad Sadeghi Meibodi, \\ Email: meibodi@gums.ac.ir}

Received 19 April 2020 Accepted 2 July 2020 Published online 28 July 2020

Keywords: Chronic total occlusion, Vitamin D, Coronary collateral circulation

\begin{abstract}
Introduction: In patients with coronary chronic total occlusion (CTO), adequate coronary collateral circulation (CCC) supports myocardial tissue versus ischemia. Vitamin D deficiency is a risk factor for osteoporosis and other chronic diseases, including type 1 diabetes, hypertension, metabolic syndrome and ischemic heart disease.

Objectives: In this study, we evaluated whether coronary CTO is associated with serum levels of vitamin D and CCC.

Patients and Methods: Around 216 patients with coronary CTO at coronary angiography were incorporated in this investigation. Serum 25(OH)D level and low-density lipoprotein (LDL-C), triglyceride (TG), total cholesterol, fasting blood sugar (FBS), serum creatinine, high-density lipoprotein (HDL-C), were assessed before angiography. Patients were divided into a poor coronary collateral circulation group (Rentrop grades 0-1) or good coronary collateral circulation group (Rentrop grades 2-3).

Results: A total of 216 patients (mean age 61.48 \pm 9.5 years) were included in this study. Regression analysis results displayed that serum $25(\mathrm{OH}) \mathrm{D}$ level had a significant correlation with CCC according to Rentrop scoring system $(P<0.0001)$. We also found that variables such as gender $(P=0.05), \operatorname{HDL}-\mathrm{C}(P=0.01)$ and serum creatinine $(P=0.05)$ were a predictor for CCC. This model described $33 \%$ of the CCC's variance in the study patients. Besides, in the analysis of clinical levels of vitamin D, it can be stated that the probability of having a high degree of Rentrop criterion in the patients with adequate level of vitamin D is 24.5 times higher than the patients with vitamin D deficiency $(P<0.001)$.

Conclusion: The results of this study emphasize the importance of informing patients with CTO commonly associated with serum vitamin D level.
\end{abstract}

Citation: Mirbolouk F, Salari A, Ashouri A, Ghoreishi N, Karimi A, Moayerifar M, et al. Correlation of plasma vitamin D levels with coronary collateral circulation. Immunopathol Persa. 2021;7(1):e10. DOI: 10.34172 ipp.2021.10.

\section{Introduction}

Coronary artery disease is the single largest reason for mortality in developed countries (1). The interest in coronary collateral circulation (CCC) as "natural bypasses" is growing, especially in patients with severe coronary atherosclerosis that leading to conventional revascularization $(2,3)$. Collateral arteries, therefore, provide an alternative source of blood supply to myocardium that has been jeopardized by occlusive coronary artery disease and they can help to preserve myocardial function in the setting of coronary artery disease (4).

Recent research shows that the presence of sufficient CCC following coronary occlusion may help to keep myocardial function via restricting the infarct area (5) and may have a remarkable effect on survival rate (6). However, the fundamental physiologic and pathologic factors influencing the development of CCC

\section{Key point}

In a cross-sectional study on 216 patients with coronary chronic total occlusion at coronary angiography, we found low serum 25-hydroxyvitamin D $(25[\mathrm{OH}] \mathrm{D})$ levels may be a valuable prognosis for poor coronary collateral circulation related to defective collaterals.

remain unknown.

In fact, the presence of chronic total occlusion (CTO) is another valuable process that leads to coronary collateral growth. These chronically occurring collaterals to CTO also have different protective effects on myocardial viability, renovation and cardiovascular consequences (7). A prior investigation demonstrated that $18.4 \%$ of patients with coronary artery disease who are referred for angiography suffered from CTO (8).

Vitamin D has a close association with

\footnotetext{
Copyright $\odot 2021$ The Author(s); Published by Nickan Research Institute. This is an open-access article distributed under the terms of the Creative Commons Attribution License (http://creativecommons.org/licenses/by/4.0), which permits unrestricted use, distribution, and reproduction in any medium, provided the original work is properly cited.
} 
cardiovascular health (9). It is synthesized in the skin from 7-dehydrocholestrol through the activity of UV radiation and is converted to its active form of 1,25-dihydroxy vitamin $\mathrm{D}$ in the kidneys $(10,11)$. Recent studies have shown that vitamin $\mathrm{D}$ has receptors on vascular endothelium, smooth and cardiac muscles (12). Vitamin D functions as a protective factor versus cardiac hypertrophy and myocardial dysfunction. Vitamin D insufficiency has been detected in various diseases, such as high blood pressure, diabetes and metabolic syndrome (13-15).

Additionally, the evidence suggests a positive relationship between serum vitamin $\mathrm{D}$ levels and the development of collateral vessels in a totally obstructed artery (16). Moreover, the effect of serum vitamin D levels on collateralization grade of CTO artery has been shown and also a positive correlation was observed $(5,16)$. Figure 1 indicates that the 1,25-dihydroxyvitamin D plays a pro-angiogenic role on endothelial and endothelial progenitor cells.

There is evidence that supports a positive correlation of vitamin $\mathrm{D}$ with arteriogenesis and angiogenesis, however its association with CCC has been regarded by few studies (5).

\section{Objectives}

Because of limited data regarding the role of vitamin D level in development of CCC in patients with CTO, we aimed to investigate whether there is a relationship between serum 25-hydroxy-vitamin D levels and development of CCC in patients with coronary CTO.

\section{Patients and Methods}

\section{Study design}

A total of 216 subjects with CTO and stenosis in at least one coronary artery undergoing coronary angiography between March 2018 and July 2019 were studied at Dr. Heshmat teaching and therapeutic center in Rasht.

Exclusion criteria were including; having a history of acute coronary syndromes within the previous three months, coronary bypass surgery and chronic renal failure (creatinine $>1.4 \mathrm{mg} / \mathrm{dL}$ ), chronic pulmonary disease, chronic inflammatory disease, severe cardiac valvular diseases and also known malignity and patients with active infection.

All subjects were screened for hypertension, diabetes and smoking history (current or former smoker). Moreover, patients who were taking antihypertensive medication were considered to have high blood pressure.

To collect the data, Judkins technique was used in coronary angiography on all patients. Two experienced cardiologists were examined the angiograms and evaluation of CCC. Patients were divided into a poor CCC group (Rentrop grades 0 -1) or good coronary collateral circulation group (Rentrop grades 2-3). Serum 25(OH) $\mathrm{D}$ levels were measured with a high performance liquid chromatography (HPLC) device using the chromatographic

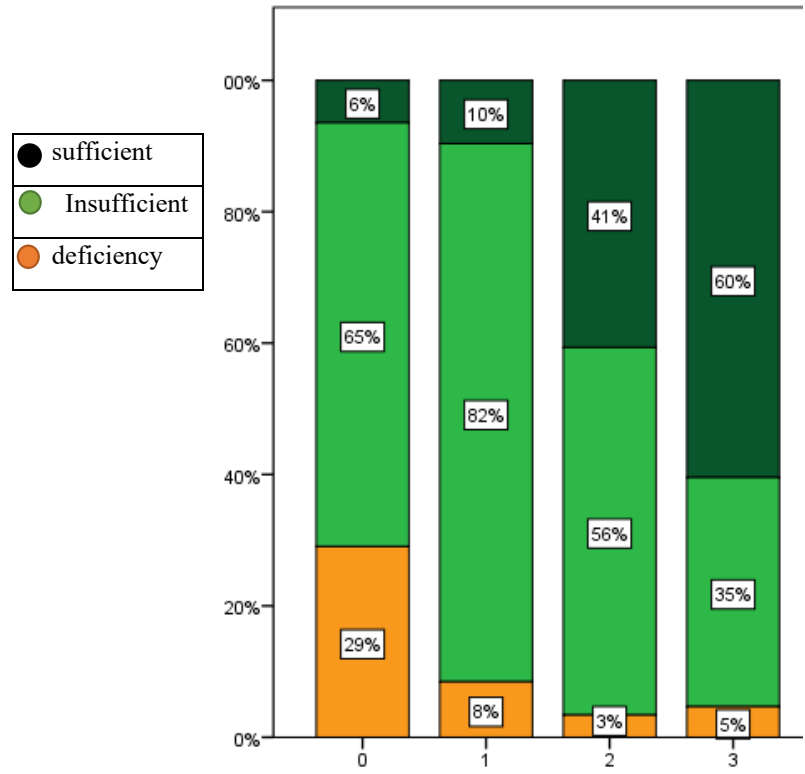

Figure 1. Frequency of different levels of coronary collateral circulation (Based on Rentrop criteria) and different levels of vitamin D in the studied patients.

method (Shimadzu LC 20AD/T, Kyoto, Japan). Serum creatinine, high-density lipoprotein (HDL-C), low-density lipoprotein (LDL-C), TG, total cholesterol, fasting blood sugar (FBS) levels were also measured in blood samples drawn by standard kits.

\section{Ethical issues}

The research followed the tenets of the Declaration of Helsinki. The study was approved by the ethics committee of this university (\#IR.GUMS.REC.1397.155). Accordingly, informed consent was obtained from all the patients. Additionally, this paper was extracted from the residential thesis of Nazila Ghoreishi, department of cardiology, Heshmat hospital, school of medicine, Guilan University of Medical Sciences.

\section{Statistical analysis}

The collected data were analyzed by SPSS software. To compare the relationship between serum $25 \mathrm{D}$ level, Rentrop score the Pearson's and Spearman's correlation coefficient was used. Chi-square test was used to contrast classification data between two groups and odds ratios were calculated using multivariate logistic regression. A $P$ value lower than 0.05 was considered as significance level.

\section{Results}

A total of 216 patients (mean age $61.48 \pm 9.5$ years) were included in this study. Mean age, gender, body mass index (BMI), smoking history, ejection fraction, presence of diabetes mellitus and hypertension were similar in the two groups. According to the findings of angiography, the most common coronary artery involvement (21.9\%) 
was three vessels. Around $38 \%$ of patients had grade one cardiovascular lateral branch filling and $63 \%$ of patients had $25(\mathrm{OH})$ D levels in the range of 11 to $30(\mathrm{ng} / \mathrm{mL})$.

According to Table 1 and Figure 1, a significant relationship between the amount of CCC and serum $25(\mathrm{OH}) \mathrm{D}$ level was detected $(P<0.001)$. There were significant relationships between the amount of filling of the lateral branches of the heart vessels with gender $(P=0.05)$, serum HDL-C $(P=0.01)$ and creatinine $(P=0.05)$. We also found, a lower degree of filling of the lateral branches of the cardiovascular system in women $(P=0.099)$; however, the magnitude of the correlation coefficient indicates the strength of the association was weak $(r=-0.101)$ and was not significant. Likewise, a weak linear relationship between the branches of the coronary circulation and serum creatinine levels was found $(\mathrm{r}=$ 0.122, $P=0.073$ ). In addition, patients with grade one myocardial infarction had a higher mean serum creatinine level than patients with grade three cardiac myocardial infarction $(P=0.008$; Tables $1-3)$.

There were significant relationships between serum 25(OH) D level and gender $(P=0.024)$, systolic blood pressure $(P=0.04)$, fasting blood sugar $(P=0.051)$ and hemoglobin levels $(P=0.005)$. The data analysis showed that women had a significantly lower level of vitamin D than men $(P<0.05)$. We found patients with higher levels of vitamin $\mathrm{D}$ had lower systolic blood pressure, higher hemoglobin levels and lower fasting blood sugar (Tables 2 and 3 ).

Regression analysis results displayed that plasma vitamin D had significant correlation with CCC according to the Rentrop scoring system $(P<0.001)$.

Accordingly, in the regression model with only the presence of variable vitamin $\mathrm{D}$, a picomole per liter increase in vitamin $\mathrm{D}$ increased the odds of having a greater filling of lateral branches of the cardiovascular system by 1.13 times (95\% CI: 1.10-1.16). In other words, an increase in vitamin D level would increase the chance of filling most of the lateral branches of the cardiovascular system by $13 \%$.

This model described 33\% of the CCC's variance in the study patients. Besides, if clinical levels of vitamin D are considered in the analysis, it can be stated that the probability of having a high degree of Rentrop criterion in the patients with adequate level of vitamin D is 24.5 times higher than the patients with vitamin $\mathrm{D}$ deficiency

Table 1. Demographic and clinical characteristics of patients under study, by degree of filling of lateral branches of the cardiovascular system ( $\mathrm{n}=216$ )

\begin{tabular}{|c|c|c|c|c|c|}
\hline \multirow{2}{*}{ Variable } & \multicolumn{4}{|c|}{ Rentrop criteria } & \multirow{2}{*}{$P$ value } \\
\hline & $0(n=31)$ & $1(n=59)$ & $2(n=83)$ & $3(n=43)$ & \\
\hline Gender (male), No. (\%) & $18(14.2)$ & $45(35.4)$ & $31(24.4)$ & $33(26)$ & 0.05 \\
\hline LDL-C $(\mathrm{mg} / \mathrm{dL})^{*}$ & $79(68-130)$ & $78(62.6-104.5)$ & $95(70.2-125)$ & $94.5(66.8-111)$ & 0.31 \\
\hline $\mathrm{HDL}-\mathrm{C}(\mathrm{mg} / \mathrm{dL})^{*}$ & $36(32-43)$ & $42(37-45)$ & $40(36-45)$ & $40(33-44)$ & 0.01 \\
\hline Hemoglobin $(\mathrm{g} / \mathrm{dL})^{*}$ & $13(11-13.4)$ & $12.4(11.4-13.7)$ & $12.8(11.3-13.8)$ & $12.7(10.8-14.1)$ & 0.9 \\
\hline Creatinine $(\mathrm{mg} / \mathrm{dL})^{*}$ & $0.91(0.86-0.99)$ & $0.88(0.78-1.01)$ & $0.9(0.81-1.01)$ & $0.98(0.85-1.1)$ & 0.05 \\
\hline Cholesterol $(\mathrm{mg} / \mathrm{dL})^{*}$ & $157(131-209$ & $151(131-193)$ & $167(140-200)$ & $168(132-180)$ & 0.67 \\
\hline Triglyceride $(\mathrm{mg} / \mathrm{dL})^{*}$ & $146(121-231)$ & $141(98-195)$ & $148(116-194)$ & $137(104-194)$ & 0.656 \\
\hline Systolic blood pressure $(\mathrm{mm} \mathrm{Hg})^{*}$ & $120(110-130)$ & $125(110-130)$ & $120(115-130)$ & $120(110-130)$ & 0.611 \\
\hline Diastolic blood pressure $(\mathrm{mm} \mathrm{Hg})^{*}$ & $80(60-80)$ & $80(70-80)$ & $80(70-80)$ & $80(70-80)$ & 0.524 \\
\hline FBS $(\mathrm{mg} / \mathrm{dL})^{*}$ & $109(100-175)$ & $131(100-194)$ & $120(94-206)$ & $122(107-172)$ & 0.435 \\
\hline
\end{tabular}

* Median values (25th and 75 th percentile); ${ }^{* *}$ Chi-square.

Table 2. Demographic and clinical characteristics of the patients under study according to vitamin $D$ level $(n=216)$

\begin{tabular}{|c|c|c|c|c|}
\hline \multirow{2}{*}{ Variable } & \multicolumn{3}{|c|}{ Vitamin D levels (ng/mL) } & \multirow{2}{*}{$P$ value $^{* *}$} \\
\hline & Deficiency $(n=20)$ & Inadequate $(n=136)$ & Enough $(n=60)$ & \\
\hline Gender (male), Ni. (\%) & $8(6.3)$ & $76(59.8)$ & $43(33.9)$ & 0.024 \\
\hline LDL-c $(\mathrm{mg} / \mathrm{dL})^{*}$ & $89.1(74.5-119.15)$ & $82.1(64.25-116)$ & $92.7(63.75-111.8)$ & 0.494 \\
\hline $\mathrm{HDL}-\mathrm{c}(\mathrm{mg} / \mathrm{dL})^{*}$ & $44(26.25-47.25)$ & $40.5(35-45)$ & $40(33-44)$ & 0.369 \\
\hline Hemoglobin $(\mathrm{g} / \mathrm{dL})^{*}$ & $12.3(11.38-13.175)$ & $12.2(10.93-13.5)$ & $13.05(12.2-14.2)$ & 0.011 \\
\hline Creatinine $(\mathrm{mg} / \mathrm{dL})^{*}$ & $0.91(0.81-1.0925)$ & $0.91(0.81-1.01)$ & $0.9(1.0775-0.8)$ & 0.885 \\
\hline Cholesterol $(\mathrm{mg} / \mathrm{dL})^{*}$ & $162(133-208.5)$ & $159(132-194.75)$ & $163(138.5-180.75)$ & 0.92 \\
\hline Triglyceride $(\mathrm{mg} / \mathrm{dL})^{*}$ & $140.5(100.5-172.25)$ & 143 (104.75-182.75) & $151(121.25-216)$ & 0.38 \\
\hline Systolic blood pressure $(\mathrm{mm} \mathrm{Hg})^{*}$ & $120(120-140)$ & $120(110-130)$ & $120(110-130)$ & 0.112 \\
\hline Diastolic blood pressure $(\mathrm{mm} \mathrm{Hg})^{*}$ & $80(70-80)$ & $80(70-80)$ & $80(70-80)$ & 0.379 \\
\hline Fasting blood sugar $(\mathrm{mg} / \mathrm{dL})^{*}$ & $126(103-218)$ & $130(100-194)$ & $117.5(151.75-98)$ & 0.23 \\
\hline
\end{tabular}

* Median values (25th and 75 th percentile); ** Chi-square. 
Table 3. Correlation between quantitative characteristics of the patients with coronary collateral circulation (CCC) and vitamin D

\begin{tabular}{|c|c|c|c|c|}
\hline \multirow{2}{*}{ Variable } & \multicolumn{2}{|c|}{ CCC } & \multicolumn{2}{|c|}{ Vitamin $\mathrm{D}(\mathrm{ng} / \mathrm{mL})$} \\
\hline & $\mathbf{r}^{*}$ & $P$ value $^{* * *}$ & $\mathbf{r}$ & $P$ value \\
\hline LDL-C (mg/dL) & 0.061 & 0.37 & -0.01 & 0.886 \\
\hline HDL-C (mg/dL) & 0.31 & 0.648 & -0.066 & 0.38 \\
\hline Hemoglobin $(\mathrm{g} / \mathrm{dL})$ & 0.035 & 0.611 & 0.191 & 0.005 \\
\hline Creatinine $(\mathrm{mg} / \mathrm{dL})^{*}$ & 0.122 & 0.073 & 0.000 & 0.998 \\
\hline Cholesterol (mg/dL) & 0.036 & 0.602 & 0.022 & 0.751 \\
\hline Triglyceride (mg/dL) & -0.047 & 0.496 & 0.059 & 0.389 \\
\hline Systolic blood pressure $(\mathrm{mm} \mathrm{Hg})$ & -0.065 & 0.339 & -0.119 & 0.04 \\
\hline Diastolic blood pressure (mm Hg) & -0.05 & 0.461 & -0.088 & 0.199 \\
\hline FBS (mg/dL) & 0.01 & 0.888 & -0.119 & 0.051 \\
\hline
\end{tabular}

* Spearman's correlation; ** $P<0.05$ significance level.

Table 4. Estimated regression coefficients of vitamin D level with cardiac vascular fillings risk

\begin{tabular}{|c|c|c|c|c|}
\hline Model & Vitamin $D(n g / m L)$ & Odds ratio & $P$ value* & $95 \% \mathrm{Cl}$ \\
\hline Model 1 & Vitamin D & 1.13 & $<0.001$ & $1.98-1.161$ \\
\hline \multirow[t]{2}{*}{ Model 2} & Adequate vitamin $D$ levels to vitamin D deficiency levels & 24.492 & $<0.001$ & $8.748-68.57$ \\
\hline & Inadequate vitamin D levels to vitamin D deficiency levels & 3.506 & $<0.007$ & $1.417-8.677$ \\
\hline
\end{tabular}

$* P<0.05$ significance level

$(P=<0.001,95 \%$ CI: 8.748-68.57; Table 4$)$.

\section{Discussion}

Coronary collateral vessels play essential roles in the coronary artery disease (CAD) patients who do not have eligibility for revascularization. In patients with acute myocardial infarction, good collateral development can be beneficial by restriction of infarct area and subsequently increased survival rate (6). Related research shows that some factors could be helpful to coronary collateral development such as degree of coronary artery stenosis, myocardial ischemia, presence of total occlusion, physical exercise, body mass index, smoking, hyperlipidemia, diabetes mellitus, age and genetic factors (16). However, the exact physiologic and pathologic mechanisms affecting the development of CCC have not yet been known.

Several studies reported the vascular endothelial cells have fundamental roles in the maturation of coronary collaterals $(17,18)$. It seems that vitamin D deficiency plays a pivotal role in CCC development via abnormalities in leukocyte adhesion, proliferation of vascular smooth muscle cells and vascular endothelial development factor (19).

When myocardial tissue becomes ischemic via stenosis or occlusion, mitotic activity and proliferation of endothelial and smooth muscle cells are started, then the collaterals actively progress (20). In sum, a perfect vascular endothelial function is mandatory for the process of collateral development adaptation and vascular endothelial dysfunction can disturb this system (19).

According to the findings of our research, women had poorly developed CCC than men. Besides, they had a significantly lower level of vitamin D than men. In line with our findings, Nardin et al indicated that lower levels of vitamin D were correlated with female gender (21). The study by Sahin et al demonstrated that low vitamin D levels were correlated with growth of CCC in patients with stable CAD (17). These findings were in accordance with the results of our study

Building on the finding of present study, it can be understood that Iranian women pay lower attention to their serum $25 \mathrm{D}$ levels than men. Moreover, this can have an impact on the health of the women's community, especially the cardiovascular system.

As well as, patients with grade one myocardial infarction had a higher mean creatinine level than patients with grade three cardiac myocardial infarction. Our findings are in accordance with the results of Dogan et al in 2015 (16).

In a study by Bhatt SP et al, exhibited that higher blood glucose values are associated with lower serum $25 \mathrm{D}$ levels in Asian Indian women (22). Additionally, in 2013, according to Dutta et al, study subjects who had the highest level of insulin resistance had the lowest $25 \mathrm{D}$ levels $(<10$ $\mathrm{ng} / \mathrm{mL}$ ). Therefore this finding was consistent with the results of our investigation (23).

Kota, et al represented which vitamin D deficiency had elevated blood pressure and inadequacy of vitamin $\mathrm{D}$ is associated with renin-angiotensin-aldosterone system regulation (24). A comparable review study indicated that subjects with higher level of vitamin D had lower blood pressure and a lower risk of hypertension (25). Actually, these findings are similar to the results of the present study.

Furthermore, in our investigation, patients with higher levels of hemoglobin possess higher levels of vitamin D. Of note, based on some studies, erythropoiesis can be stimulated by $1,252 \mathrm{D}$ in red blood cell precursor cells via improving erythropoietin sensitivity $(26,27)$. In this way, Ernst et al 2016 indicated that a daily vitamin D supplement 
of 2800 IU for 8 weeks does not increase hemoglobin levels in hypertensive patients with anemic status with serum 25 D levels $<75$ (ng/mL)(27).

Besides, if clinical levels of vitamin $\mathrm{D}$ are considered in the analysis, it can be stated that the probability of having a higher degree of Rentrop criterion in the patients with adequate level of vitamin D compared to the patients with vitamin D is 24.5 times. Additionally, inadequate vitamin $\mathrm{D}$ level was 3.5 times higher in patients with vitamin D deficiency. According to results of our study, we found that low vitamin D levels and CCC are correlated to each other and have stronger association with poor health status, which is closely related to inadequate vitamin $\mathrm{D}$, may also be connected with poor CCC growth in CTO patients. In spite of the fact that we demonstrated this correlation, the exact mechanism of this relation is still unknown. Dogan et al showed that poor outcomes in patients with acute coronary syndromes may even be associated with visible coronary collateral vessels (16).

\section{Conclusion}

According to the present study, patients with CTO who had lower serum 25-hydroxyvitamin D (25(OH) D) levels had poor CCC. Therefore, low serum 25-hydroxyvitamin $\mathrm{D}(25(\mathrm{OH}) \mathrm{D})$ levels may be a valuable prognosis for poor CCC. In addition, we found that one of the reasons of poor cardiovascular outcomes in patients with CAD may be defective collaterals.

\section{Limitations of the study}

The first limitation of our study is the cross-sectional design of the study that cannot provide any pathophysiological evidence on the association between low vitamin D status and CCC.

\section{Authors' contribution}

Conception and design: FM and AS; literature search and Data acquisition: NG; drafting the manuscript: MM and ZA; analysis and interpretation of data: AA; critical revision of the manuscript for important intellectual content: MG and ASM. All authors read and approved the final paper.

Conflicts of interest

The authors declare that they have no conflict of interest.

Ethical considerations

Ethical issues (including plagiarism, data fabrication, double publication) have been completely observed by the authors.

\section{Funding/Support}

This work supported by deputy research and technology of Guilan University of Medical Sciences in Iran (Grant\# 97031207).

\section{References}

1. Lu Z, Luo Z, Jia A, Muhammad I, Zeng W, Shiganmo A, et al. Effects of ABCA1 gene polymorphisms on risk factors, susceptibility and severity of coronary artery disease. Postgrad Med J. 2020. doi: 10.1136/postgradmedj-2019-136917

2. Seiler C. The human coronary collateral circulation.
Eur J Clin Invest. 2010;40:465-76. doi: 10.1111/j.13652362.2010.02282.x

3. Allahwala UK, Kott K, Bland A, Ward M, Bhindi R. Predictors and prognostic implications of well-matured coronary collateral circulation in patients with a chronic total occlusion (CTO). Int Heart J. 2020:19-456. doi: 10.1536/ihj.19-456.

4. Huang M, Zheng J, Chen Z, You C, Huang Q. The relationship between circulating neuregulin-1 and coronary collateral circulation in patients with coronary artery disease. Int Heart J. 2020;61:115-20. doi: 10.1536/ihj.19-277.

5. Lima Jr J, Kunadian V. Vitamin D: evidence for an association with coronary collateral circulation development? Postepy Kardiol Interwencyjnej. 2015;11:174. doi: 10.5114/ pwki.2015.54008

6. You X-D, Jin J-L, Zhang H, Guo N, Hou B-J, Guo Y-L, et al. Lipoprotein (a) as a marker for predicting coronary collateral circulation in patients with acute myocardial infarction. Per Med. 2020;17:67-78. doi: 10.2217/pme-2018-0127.

7. Allahwala UK, Brilakis ES, Byrne J, Davies JE, Ward MR, Weaver JC, et al. Applicability and Interpretation of coronary physiology in the setting of a chronic total occlusion. Circ Cardiovasc Interv. 2019;12:e007813. doi: 10.1161/ CIRCINTERVENTIONS.119.007813.

8. Fefer P, Knudtson ML, Cheema AN, Galbraith PD, Osherov AB, Yalonetsky $\mathrm{S}$, et al. Current perspectives on coronary chronic total occlusions: the Canadian Multicenter Chronic Total Occlusions Registry. J Am Coll Cardiol. 2012;59:991-7. doi: 10.1016/j.jacc.2011.12.007.

9. Pilz S, Verheyen N, Grübler MR, Tomaschitz A, März W. Vitamin D and cardiovascular disease prevention. Nat Rev Cardiol. 2016;13:404. doi: 10.1038/nrcardio.2016.73.

10. Nadir MA, Szwejkowski BR, Witham MD. Vitamin D and cardiovascular prevention. Nat Rev Cardiol. 2010;28:e5-e12. doi: 10.1038/nrcardio.2016.73.

11. Dimakopoulos I, Magriplis E, Mitsopoulou A-V, Karageorgou D, Bakogianni I, Micha R, et al. Intake and contribution of food groups to vitamin $\mathrm{D}$ intake in a representative sample of adult Greek population. Nutrition. 2020;72:110641. doi: 10.1016/j. nut.2019.110641.

12. Song J, Chen X, Cheng L, Rao M, Chen K, Zhang N, et al. Vitamin $D$ receptor restricts $T$ helper 2-biased inflammation in the heart. Cardiovasc Res. 2018;114:870-9. doi: 10.1093/ cvr/cvy034.

13. He S, Hao X. The effect of vitamin D3 on blood pressure in people with vitamin D deficiency: A system review and meta-analysis. Medicine (Baltimore). 2019;98:e15284. doi: 10.1097/MD.0000000000015284.

14. Yammine K, Wehbe R, Assi C. A systematic review on the efficacy of Vitamin D supplementation on diabetic peripheral neuropathy. Clin Nutr . 2020. doi: 10.1016/j.clnu.2020.01.022

15. Wieder-Huszla S, Jurczak A, Szkup M, Barczak K, Dołęgowska B, Schneider-Matyka D, et al. Relationships between vitamin d3 and metabolic syndrome. Int J Environ Res Public Health 2019;16:175. doi: 10.3390/ijerph16020175

16. Dogan Y, Sarli B, Baktir AO, Kurtul S, Akpek M, Sahin O, et al. 25-Hydroxy-vitamin D level may predict presence of coronary collaterals in patients with chronic coronary total occlusion. Postepy Kardiol Interwencyjnej. 2015;11:191. doi: 10.5114/ pwki.2015.54012.

17. Uysal OK, Sahin DY, Duran M, Turkoglu C, Yıldırım A, Elbasan Z, et al. Association between uric acid and coronary collateral circulation in patients with stable coronary artery disease. Angiology. 2014;65:227-31. doi: 10.1177/0003319713500706

18. Liao LS, Bai YP. The dynamics of monocytes in the process 
of collateralization. Aging Med (Milton). 2019;2:50-5. doi: 10.1002/agm2.12054

19. Söğüt E, Kadı H, Karayakalı M, Mertoğlu C. The association of plasma vitamin $\mathrm{A}$ and $\mathrm{E}$ levels with coronary collateral circulation. Atherosclerosis. 2015;239:547-51. doi: 10.1016/j. atherosclerosis.2015.02.029

20. Ozaki K, Tanaka T. Molecular genetics of coronary artery disease. J Hum Genet. 2016;61:71. doi: 10.1038/jhg.2015.70

21. Nardin M, Verdoia M, Schaffer A, Barbieri L, Marino P, De Luca G, et al. Vitamin D status, diabetes mellitus and coronary artery disease in patients undergoing coronary angiography. Atherosclerosis. 2016;250:114-21. doi: 10.1016/j. atherosclerosis.2016.05.019

22. Bhatt SP, Misra A, Gulati S, Singh N, Pandey RM. Lower vitamin $\mathrm{D}$ levels are associated with higher blood glucose levels in Asian Indian women with pre-diabetes: a population-based cross-sectional study in North India. BMJ Open Diabetes Res Care. 2018;6:e000501. doi: 10.1136/bmjdrc-2017-000501

23. Dutta D, Maisnam I, Shrivastava A, Sinha A, Ghosh S, Mukhopadhyay $P$, et al. Serum vitamin-D predicts insulin resistance in individuals with prediabetes. Indian J Med Res.
2013;138:853.

24. Kota SK, Kota SK, Jammula S, Meher LK, Panda S, Tripathy PR, et al. Renin-angiotensin system activity in vitamin $D$ deficient, obese individuals with hypertension: An urban Indian study. Indian J Endocrinol Metab. 2011;15:S395. doi: 10.4103/22308210.86985

25. Ullah MI, Uwaifo GI, Nicholas WC, Koch CA. Does vitamin d deficiency cause hypertension? Current evidence from clinical studies and potential mechanisms. Int J Endocrinol. 2010;2010:579640. doi: 10.1155/2010/579640.

26. Zittermann A, Ernst JB, Birschmann I, Dittrich M. Effect of vitamin $\mathrm{D}$ or activated vitamin $\mathrm{D}$ on circulating 1, 25-dihydroxyvitamin D concentrations: a systematic review and metaanalysis of randomized controlled trials. Clin Chem. 2015;61:1484-94. doi: 10.1373/clinchem.2015.244913.

27. Ernst JB, Tomaschitz A, Grübler MR, Gaksch M, Kienreich $\mathrm{K}$, Verheyen $\mathrm{N}$, et al. Vitamin D supplementation and hemoglobin levels in hypertensive patients: a randomized controlled trial. Int J Endocrinol. 2016;2016:6836402. doi:10.1155/2016/6836402. 